\title{
Demystifying Inhaler Use in Chronic Obstructive Airways Disease
}

\author{
Matteo Bonini, MD, PhD, Omar S. Usmani, MD, PhD
}

National Heart and Lung Institute (NHLI), Imperial College London \& Royal Brompton Hospital, UK

\section{ABSTRACT}

Chronic obstructive airways diseases afflict millions of people worldwide, being responsible for significant morbidity and mortality. Despite progresses in the understanding of the pathophysiological mechanisms and advances in the therapeutic interventions, neither asthma nor chronic obstructive pulmonary disease (COPD) can be cured as yet, although both diseases can be optimally controlled. Inhaler therapy plays a crucial role in achieving this and allows personalised treatment strategies to patients. However, satisfactory adherence and correct technique in the use of inhaler devices can be particularly challenging. The present review aims to present updated and evidence-based literature findings to shed light on the role and relevance of inhaler devices in chronic obstructive airways diseases and provide readers with clear information and advice about the use of inhalers in the variety of options available, to recognise the crucial inhaler errors and gain an insight with respect to recent innovation addressing the unmet needs in the field. (BRN Rev. 2018;4(4):304-18) Corresponding author: Matteo Bonini,m.bonini@imperial.ac.uk

Key words: Adherence. Airways. Device. Inhaler. 


\section{INTRODUCTION}

Asthma and chronic obstructive pulmonary disease (COPD) are widespread chronic obstructive airways diseases that afflict a vast number of individuals, being responsible for significant morbidity and mortality ${ }^{1}$. Approximately 300 million people worldwide suffer from asthma, with an additional 100 million subjects estimated to be affected by $2025^{2}$. Likewise, around 15 million people have a physician-diagnosis of COPD in the United States ${ }^{3}$. Of relevance, COPD has been ranked among the top leading causes of death in the world ${ }^{4}$ and, together with asthma, dramatically affects patients' quality of life ${ }^{5}$. These overwhelming figures translate into significant healthcare costs and a considerable socio-economic burden ${ }^{6}$.

Despite progresses in the understanding of the pathophysiological mechanisms and advances in the development of new therapeutic strategies, neither asthma nor COPD can be cured, as yet. However, both diseases can be optimally controlled, and the role of inhaler devices is crucial in achieving this by personalising treatment strategies to patients ${ }^{7}$. Inhalation therapy is the mainstay of treatment in patients with chronic respiratory conditions, where bronchodilators (i.e. beta ${ }_{2}$ agonists and anti-muscarinic agents) and anti-inflammatory drugs (i.e. glucocorticoids) are recommended by international strategy documents, at any stage of disease severity ${ }^{8,9}$. Inhaled treatment has indeed several advantages over systemic therapy allowing the delivery of active molecules directly to the target site of action, whilst minimising side effects and adverse events ${ }^{10}$. Furthermore, compared with oral administration, a lower quantity of drug dose is needed to achieve the therapeutic effect and the onset of action is more rapid through the inhaled route $^{11}$.

However, the use of inhaler devices in asthma and COPD can be challenging. Studies demonstrate significant misuse in handling, as well as non-adherence towards recommended treatment regimens, which are key issues in the therapeutic efficacy and health economics of inhaled pharmacological interventions ${ }^{12,13}$. The features contributing to adherence to inhaled medications are complex, but a crucial element is patients having the correct inhaler technique to ensure adequate drug delivery, otherwise, erroneously, they may feel the device is ineffective ${ }^{14}$. A recent systematic review conducted to identify main errors in inhaler use and their impact on health outcomes and resources, showed wide heterogeneity in the term "critical error"; where 299 definitions were identified in the scientific literature ${ }^{15}$. The authors also observed an important association between inhaler misuse and worsened health outcomes, highlighting the importance of achieving optimal inhaler technique and the need for a consensus on the definition of critical and non-critical errors. Furthermore, with over 200 available drug-inhaler device combinations (Fig. 1), significant confusion may arise for healthcare professionals, and matching the patient's characteristics, needs and preferences to the most appropriate inhaler device becomes crucial. Indeed, most prescribers in pulmonary medicine focus on the class medication and specific drug molecule, but the importance of pertinent inhaler selection is becoming increasingly recognised in achieving disease control ${ }^{16}$.

This present review aims to present updated and evidence-based literature findings to shed light on the role and relevance of inhaler devices 

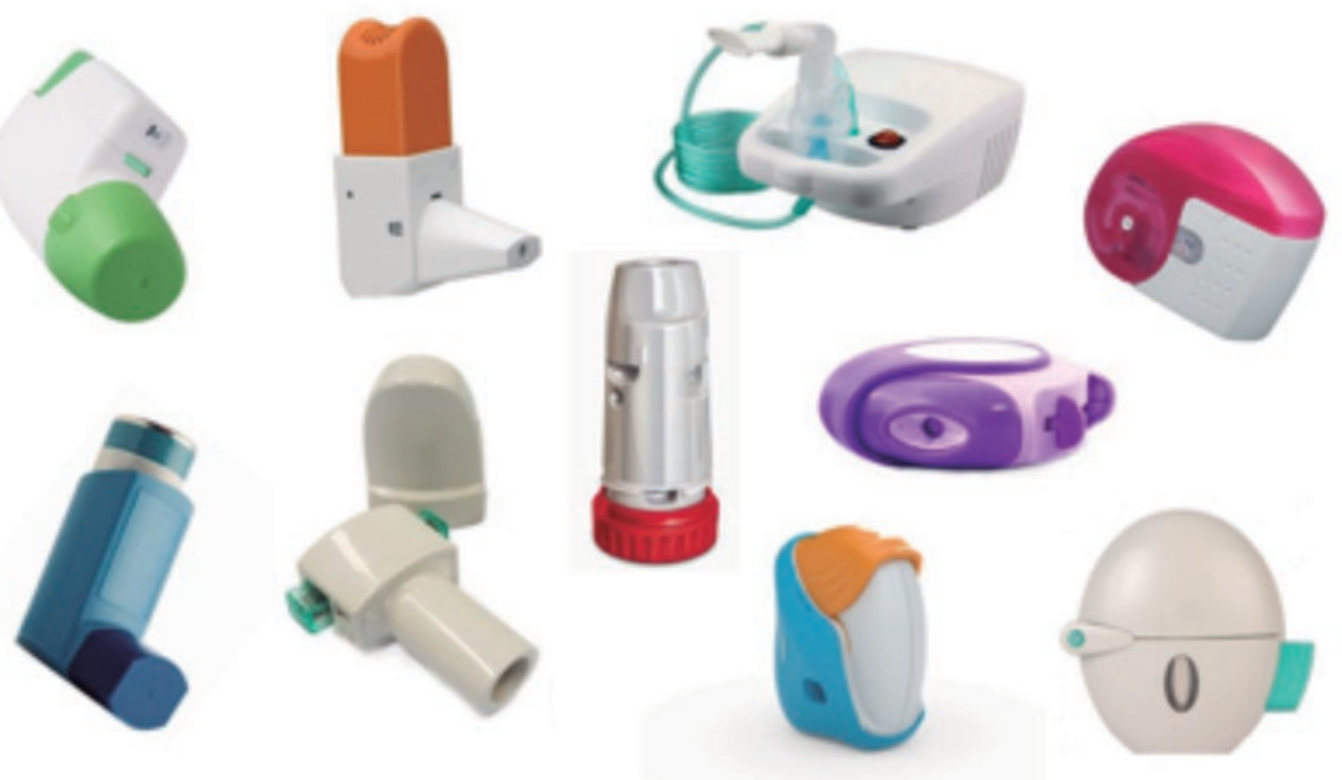

Figure 1. Examples of available inhaler devices.

in chronic airways diseases, provide readers with clear information and advice about the use of inhalers, in the variety of options available in day-to-day practice, to recognise the key inhaler errors and gain an insight with respect to recent innovation addressing the unmet needs in the field.

\section{THE RANGE OF CURRENTLY AVAILABLE INHALER DEVICES}

Aerosols, either solutions containing the medication or solid drug particles suspended in gas or dry powder, can be delivered through pressurised metered-dose inhalers (pMDIs), dry powder inhalers (DPIs), soft-mist inhalers (SMIs) or nebulisers (Table 1). In recent years, several technological innovations in device engineering and formulation science have significantly improved the performance of all existing inhaler categories, with the new generation of devices having pulmonary deposition fractions of $40-50 \%$ the nominal dose ${ }^{17}$.

Pressurised metered-dose inhalers are compact devices that require no agent preparation and offer high dose-to-dose reproducibility. The first commercial pMDI was developed in the late 1950's by Riker Laboratories as a portable, multi-dose delivery device for bronchodilator drugs ${ }^{7}$. The subsequent generation of pMDIs consisted of aluminium canisters, containing a pressurised suspension of micronised drug particles dispersed in chlorofluorocarbon (CFC) propellants. In suspension formulations, active drugs are not soluble in the propellant and remain in a state of solid powder, making 
TABLE 1. Main characteristics of available inhaler devices

\begin{tabular}{|c|c|c|c|}
\hline Devices & Advantages & Disadvantages & Instructions for patients \\
\hline $\begin{array}{l}\text { Pressurised } \\
\text { metered-dose } \\
\text { inhalers (pMDIs) }\end{array}$ & $\begin{array}{l}\text { Portable; not dependent on } \\
\text { inspiratory flow; reproducible } \\
\text { dosing; wide variety of drugs } \\
\text { available; no contamination risk; } \\
\text { low cost }\end{array}$ & $\begin{array}{l}\text { Ozone-depleting properties (chloroflu- } \\
\text { orocarbon- [CFC] driven); better } \\
\text { perform with spacers (CFC-driven); } \\
\text { need to be shaken prior use } \\
\text { (CFC-driven); hand-breath } \\
\text { coordination required; high } \\
\text { oropharyngeal deposition; cold } \\
\text { freon effect }\end{array}$ & $\begin{array}{l}\text { Shake well (CFC-driven); prime inhaler the } \\
\text { first time; hold inhaler upright; exhale } \\
\text { fully; seal lips around the mouthpiece; } \\
\text { press the dose release button while } \\
\text { inhaling through the mouth slowly and } \\
\text { deeply; hold breath for 5-6 s; exhale } \\
\text { slowly }\end{array}$ \\
\hline $\begin{array}{l}\text { Dry powder inhalers } \\
\text { (DPIs) }\end{array}$ & $\begin{array}{l}\text { Portable; no hand-breath } \\
\text { coordination required; fast drug } \\
\text { delivery; dose counter or } \\
\text { individually packaged dose; no } \\
\text { spacer required }\end{array}$ & $\begin{array}{l}\text { Inspiratory flow dependent; dexterity } \\
\text { in dose loading and activation } \\
\text { needed for single-dose devices; } \\
\text { poor dose reproducibility; additional } \\
\text { devices for rescue medications } \\
\text { required }\end{array}$ & $\begin{array}{l}\text { Load and activate the dose; exhale fully; } \\
\text { seal lips around the mouthpiece; inhale } \\
\text { quickly and deeply for } 2-3 \mathrm{~s} \text {; hold breath } \\
\text { for } 5-6 \mathrm{~s} \text {; exhale slowly }\end{array}$ \\
\hline Nebulisers & $\begin{array}{l}\text { Easy to use; propellant free; no } \\
\text { hand-breath coordination } \\
\text { required; not dependent on } \\
\text { inspiratory flow; slow velocity } \\
\text { aerosol; high patient's adher- } \\
\text { ence }\end{array}$ & $\begin{array}{l}\text { Not portable; power source needed; } \\
\text { long drug delivery time; potential } \\
\text { higher risk of respiratory infections; } \\
\text { device cleaning and maintenance } \\
\text { frequently needed }\end{array}$ & $\begin{array}{l}\text { Carefully load medication dose following } \\
\text { instructions; ensure face mask is well in } \\
\text { place; inhale through the mouth slowly } \\
\text { and deeply; clean device after each use }\end{array}$ \\
\hline $\begin{array}{l}\text { Soft-mist inhalers } \\
\text { (SMIs) }\end{array}$ & $\begin{array}{l}\text { Auto lock when cartridge is } \\
\text { empty; propellant free; slow } \\
\text { velocity aerosol; long plume } \\
\text { duration; no hand-breath } \\
\text { coordination required; high fine } \\
\text { particle fraction and smaller } \\
\text { drug particle size; no spacer } \\
\text { required }\end{array}$ & $\begin{array}{l}\text { Dose loading into device required; } \\
\text { strength and dexterity needed }\end{array}$ & $\begin{array}{l}\text { Insert cartridge before use; write down } \\
\text { expire date on cartridge; prime inhaler } \\
\text { the first time; hold inhaler upright with } \\
\text { cap closed; turn base until it clicks; } \\
\text { exhale fully; seal lips around the } \\
\text { mouthpiece; inhale through the mouth } \\
\text { slowly and deeply; press the dose } \\
\text { release button and continue to inhale as } \\
\text { long as possible; hold breath for } 5-6 \mathrm{~s} \text {; } \\
\text { exhale slowly }\end{array}$ \\
\hline
\end{tabular}

it necessary to shake the device before use to ensure uniform distribution of the particles and a constant emitted dose at each actuation. However, following the Montreal Protocol Declaration banning the use of CFC propellants, due to their ozone-depleting properties, pharmaceutical companies started to develop hydrofluoroalkane (HFA) propellants ${ }^{18}$. In HFA-solution pMDIs, the drug is uniformly distributed in the canister and does not require any shaking prior to use. Currently, pMDIs represent the most commonly prescribed inhalers for drug delivery to the airways thanks to the relatively low cost and the wide variety of medications available with this technology ${ }^{19}$. Extreme temperatures and/or high altitudes may affect the drug in the pMDI. Therefore, the patient must always check the inhaler label for storage instructions. Importantly, the correct use of pMDIs requires a slow and deep inhalation and some degree of coordination is required between inhalation and device actuation ${ }^{20}$. To avoid these issues, the combined use of a pMDI with a spacer may be helpful, especially in children and elderly patients who may have problems with dexterity. There is less need however for spacers with the newer generation of HFA-solution pMDIs, as these devices have slower velocity aerosols with smaller size or fine drug particle fractions, and are less flow-dependent, meaning there is 
consistency of dose delivery to the lungs independently from the patient inhalation flow ${ }^{21}$. Breath-activated (BA) pMDIs, now available for many years, have been shown to be advantageous in patients with poor coordination ${ }^{22}$. Breath-activated-pMDIs contain a conventional pressurised canister, with a flow triggered system driven by a spring, which releases the drug dose during inhalation, so that firing and inhaling are automatically coordinated. They can be also actuated at an inhalation flow, which is easily achievable by most patients. Recent studies have shown improved drug deposition and increased patient confidence with the use of BA-pMDI's, but the greatest limiting factor for their dissemination is represented by the restrict availability of agent molecules for these particular devices ${ }^{23}$.

Dry powder inhalers are equally small and portable inhaler devices. The first DPI was introduced in 1971 by Bell et al. ${ }^{24}$ to deliver therapy to COPD patients. Since then, a broad number of DPIs have entered the market, each with its own particular handling instructions and specific inhalation threshold and manoeuvre. Dry powder inhalers, particularly those of early generation, do not require coordinated activation, however they need a careful approach by the patient to dose loading and dose preparation, since an incorrectly prepared DPI will be clinically ineffective even with optimal handling and inhalation technique. Dry powder inhaler devices can also be flow-dependent leading to variability in drug delivery to the lungs in relation to the patient inhalation flow through the device ${ }^{25}$. In addition, most conventional DPIs are influenced by the energy in the patient inhalation for breaking apart and dispersing the dry powder contained in the device. These factors may lead to reduced levels of drug deposition ( 20\%) to the lungs at low patient inhalation flows ${ }^{26}$, and recent data show an increased risk of readmission in patients discharged on DPIs following an acute exacerbation of COPD, where in this scenario they usually have suboptimal inspiratory flow rates ${ }^{27}$. Recent innovations in DPI engineering have advanced this category with a newer generation of inhalers (i.e. capsule-based and extra-fine DPIs) that are activated and achieve high levels of lung deposition ( $>40 \%$ ) even at low patient inhalation flows $(\sim 301 / \mathrm{min} \text { or less })^{28,29}$.

Nebulisers are motor-driven devices that produce a fine mist for delivery to the lungs and represent one of the earliest systems for inhalation therapy ${ }^{30}$. Commonly, nebulisers are distinguished into two main categories: jet nebulisers and ultrasonic nebulisers ${ }^{31}$. In jet nebulisers, a high-velocity air stream moves through a narrow capillary tube and carries the large droplets of liquid to baffles throughout the nebuliser, which breaks these droplets down so that they can be sufficiently small to be inhaled by the patient. On the other hand, ultrasonic nebulisers use sound waves, generated by the vibration of piezoelectric crystals at high frequency, to break down the liquid into the smaller droplets required for inhalation. Ultrasonic nebulisers are typically more expensive and less efficient than jet nebulisers, and can increase the temperature of the solution, making them unsuitable for heat-sensitive agents. Nebulisers are often used in patients who are hospitalised, with acute exacerbations or with advanced lung disease, who may be too dyspnoeic and impaired to complete a proper respiratory manoeuvre. Compared with other device categories, nebulisers may be viewed as a time-consuming and inefficient means of 
delivering aerosol medication. This is particularly evident when more than one agent is prescribed for disease management, as combination products are not widely available in all countries in a nebulised format. Another common concern with nebulisers is microbial contamination, which may expose patients to the risk of respiratory tract infections ${ }^{32}$. However, new nebuliser systems have been developed to decrease the inefficiency, waste, and variability of nebulised drug delivery. In regard to this, vibrating mesh disk nebulisers, powered by a compressor and containing a microchip, control drug delivery to the patient and have an adaptive aerosol system to pulse the inhaled drug during the inhalation. This therefore leads to less dose wastage, positively impacting on patient's adherence ${ }^{33}$. A smart nebuliser system containing an electronic smart-card unit with an air compressor to accurately dose and target aerosol delivery, has also been developed lately, showing better efficacy and patients' adherence compared to standard nebulisers ${ }^{34}$. New handheld multi-dose nebulisers have been at last newly marketed with the potential to compete with both pMDIs and DPIs on the portable inhaler market ${ }^{35}$.

At last, SMIs, equally considered to be nebulisers, are composed of propellant-free liquid solutions that are inhaled as a fine aerosol mist through a mouthpiece containing a control valve to release medication ${ }^{36}$. Soft mist inhalers deliver the drug solution using mechanical energy produced by a spring, generating a fine, slow-moving mist over a slightly longer period compared to other devices (1.2-1.5 s versus $0.15-0.35 \mathrm{~s})$. This allows patients more time to synchronise actuation and breathing, possibly reducing the errors that occur due to poor coordination ${ }^{37}$. Soft mist inhalers also offer additional technological advances such as a high fine particle fraction $(\sim 75 \%)$ and smaller drug particle size in the respirable range $\mathrm{e}^{38}$. These features lead to low levels of drug deposition in the oropharynx and high total lung deposition ( $>50 \%)$, effectively targeting the site of disease ${ }^{39}$. Patients using SMIs may require additional support in the assembly and proper priming procedures ${ }^{40}$. Like pMDIs, SMIs can also be combined with spacers, although the combination is yet to be fully evaluated.

\section{PRINCIPAL ERRORS IN INHALER USE}

Patient adherence to prescribed treatment has been shown to represent a crucial link between effective therapy and improved disease outcomes. However, several studies have revealed unsatisfactory compliance with guideline recommendations ${ }^{41}$ and inhaler therapy use (Fig. 2) ${ }^{42}$. Medication underuse, overuse, and improper use are three common forms of patient non-adherence. Adherence to inhaled corticosteroids (ICS) has been reported to be an independent strong predictor of long-term asthma control ${ }^{43}$. Furthermore, the results of a systematic review highlighted that satisfactory treatment adherence was associated with a lower risk of severe asthma exacerbations in both adult and paediatric populations ${ }^{44}$. Interestingly, Sulaiman et al. ${ }^{45}$ showed that an intervention with (bio)feedback on the features of inhaler use identified refractory asthma and enhances inhaler technique and adherence. Medication adherence is estimated to be only $10-40 \%$ in patients with COPD and decreases with time 


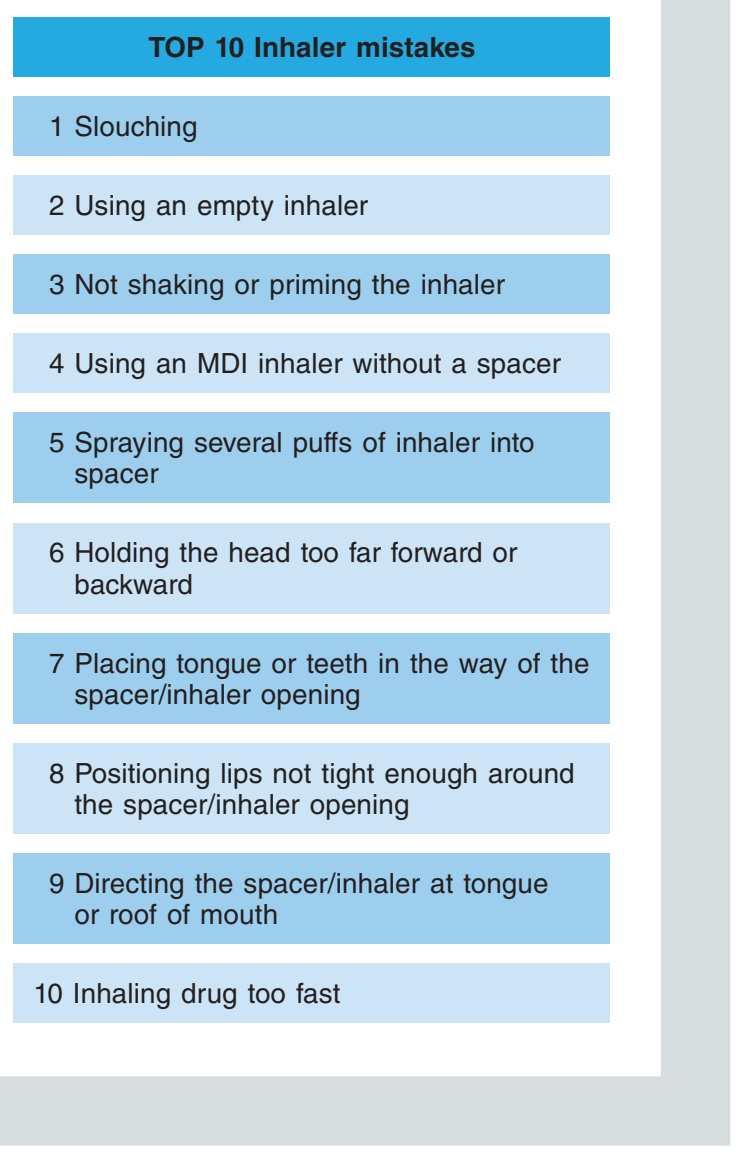

Figure 2. Top 10 inhaler mistakes. Modified from the National Jewish Health (www.njhealth.org).

MDI: metered-dose inhaler.

following the first prescription. Alarmingly, only $6 \%$ of the 244 severe COPD patients studied with an electronic audio-recording device (INCA), had an adherence rate greater than $80 \%$ following discharge from hospital $^{46}$. Distinct adherence behaviours have been shown to be associated with specific clinical outcomes in COPD ${ }^{47}$. Low adherence results in poor symptom control, worsened quality of life and mortality rates two to three times higher than those seen in patients with good compliance ${ }^{48}$. Inhaler technique error is a frequent cause of non-adherence in COPD patients, commonly associated with unscheduled healthcare resource utilisation and poor symptom control.

To properly understand and quantify device-use errors, so that patient interventions can be effectively introduced and new devices designed, it is relevant to correctly define critical and non-critical errors, as well as to carefully identify the number and type of checklist steps for each specific device. A critical error is one that may impact the effectiveness of the delivered drug and thereby lead to sub-optimal disease control, whereas a non-critical error is one of the checklist steps that is not classified as critical ${ }^{49}$.

The CRITical Inhaler mistaKes and Asthma controL (CRITIKAL) study investigated the association between specific inhaler errors and asthma outcomes, using data from the initiative Helping Asthma in Real-life Patients (iHARP) asthma review service. People with asthma receiving a fixed-dose combination treatment with inhaled glucocorticoids and long-acting $\beta_{2}$-agonists were categorised by the controller inhaler device they used (i.e. DPIs or pMDIs). The report included data from 3660 patients, and showed that insufficient inspiratory effort with DPI users was common (32-38\%) and significantly associated with uncontrolled asthma and increased exacerbation rate. In pMDI users, actuation before inhalation ( $25 \%$ of patients) was associated with uncontrolled asthma ${ }^{50}$.

A review of 21 studies addressing pMDI use revealed that the prevalence of poor inhaler technique ranged from $14 \%$ to $90 \%$ (with an average of $50 \%$ ). Furthermore, the use of multiple inhaler devices in an individual patient 
was shown to be associated with a higher prevalence of errors compared to the use of single devices ${ }^{51}$.

In a cross-sectional study ${ }^{52}$, patients with asthma were observed for serious inhaler errors by trained healthcare providers. Among 3681 asthmatics, 341 (55\%) patients made $\geq 1$ critical errors. Those most commonly observed were failure to exhale before inhalation, inadequate breath-hold at the end of inhalation, and inhalation not sufficiently forceful from the start. Factors significantly associated with $\geq 1$ serious errors included poor asthma control in the previous four weeks, as well as asthma-related hospitalisation and no inhaler technique review during the previous year. Interestingly, females and obese subjects were the demographic categories showing worse inhaler technique.

Sanchis et al. ${ }^{53}$ reported the most common errors observed during the various steps of a pMDI inhalation manoeuvre to be in breath holding $(24-77 \%)$, shaking the inhaler $(7-57 \%)$ and firing the inhaler while breathing-in slowly $(10-68 \%)$, with only a $34 \%$ weightedaverage share of patients showing adequate inhaler technique. In contrast, when assessing the errors in the inhalation manoeuvre with DPIs, they found breathing-out and breath-holding to be the major issues.

A recent meta-analysis found overall and critical error rates to be particularly high across all devices, ranging from $50 \%$ to $100 \%$ and from $14 \%$ to $92 \%$, respectively. A trend towards higher error rates was observed with devices requiring a greater number of checklist steps ${ }^{54}$, and together with other research$\mathrm{ers}^{55}$, have called for the need to standardised checklists and definitions for inhaler error studies to ensure consistency across the literature in order to interpret data meaningfully.

\section{HOW TO CHOOSE THE BEST INHALER}

While no single inhalation device is perfect, the wide variety of available device options supports tailored and optimised device selection based on patients' characteristics, needs and preferences ${ }^{56}$.

The three most important factors influencing inhaled drug deposition within the airways are the patient's inhalation flow, the aerosol velocity and the drug particle size. These factors ultimately impact on the amount of drug reaching the airways and consequently on the functional and clinical response of patients $s^{57-59}$. The choice of an inhaler device in patients with chronic airways diseases should therefore take in high consideration such parameters. In example, for patients who encounter most difficultly with coordination of actuation and inhalation, a DPI may be the most suitable device. Conversely, for patients unable to generate a hard, fast breath with an adequate peak inspiratory flow rate, a pMDI or a SMI may be a better option. A pragmatic algorithm in choosing the right inhaler device for the right patient has recently been published (Fig. 3) ${ }^{60}$, and there are standards available to check the competency of those involved in inhaler device demonstration ${ }^{61}$.

Since different inhalers have unique requirements for their individual operation, the use of more than one device in the management of respiratory diseases can create confusion about 
A

\begin{tabular}{|c|c|c|}
\hline \multicolumn{3}{|c|}{$\begin{array}{l}\text { Action 1. Assess patient's inspiratory ability-observe the patient inhaling } \\
\text { (using their own inhaler if available) }\end{array}$} \\
\hline \multicolumn{3}{|c|}{$\downarrow$} \\
\hline \multicolumn{3}{|c|}{$\begin{array}{l}\text { Ask the patient to try both of the following inhalation manouvres: } \\
\text { - Quick and deep-can the patient take a quick, deep breath in } 2-3 \text { seconds? } \\
\text { - Slow and steady-can the patient take a slow, steady and breath in over 4-5 seconds? }\end{array}$} \\
\hline $\begin{array}{l}\text { Can perform quick and deep } \\
\text { maneuobre only } \\
\downarrow\end{array}$ & $\begin{array}{l}\text { Can perform both inhalation } \\
\text { maneuobre } \\
\downarrow\end{array}$ & $\begin{array}{c}\text { Can perform slow a } \\
\text { maneuobre } 0 \\
\downarrow\end{array}$ \\
\hline Considerer a DPI & Considerer a DPI, pMDI, or SMI & Considerer a $\mathrm{pD}$ \\
\hline & $\begin{array}{l}\text { If unsure aft } \\
\text { the use of } d \\
\text { such as: } \\
\text { AIM machir } \\
\text { Device trair } \\
\text { attachment }\end{array}$ & $\begin{array}{r}\text { erving the patient, } \\
\text { to asses inspirator } \\
\\
\quad \text { Flo-Tone Tra } \\
\text { In-Check DI } \\
\text { inspiratory f }\end{array}$ \\
\hline
\end{tabular}

Select required drug formulation once inhaler device type has ben chosen, in line with local formulary

B

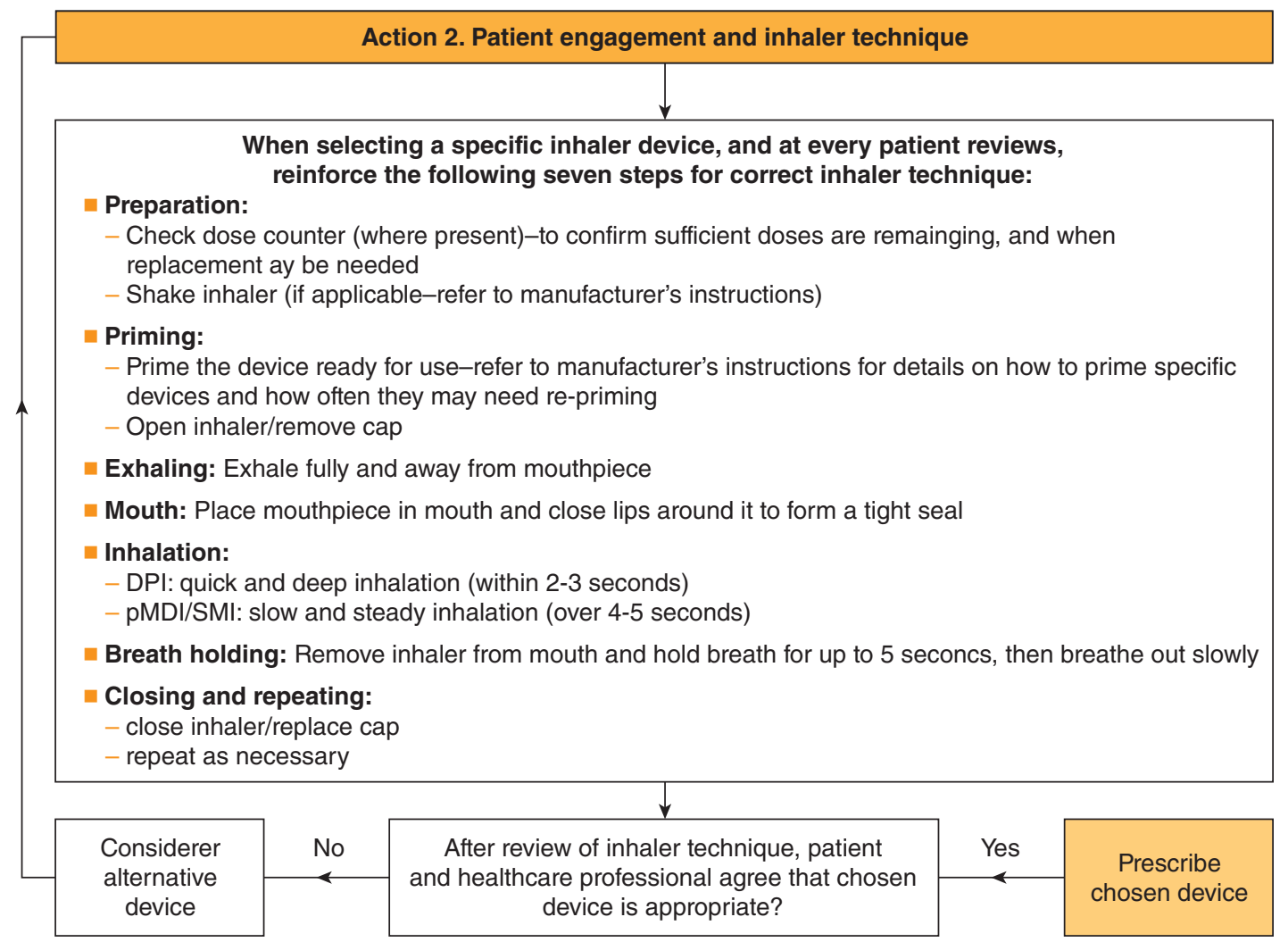

FiguRE 3. Choosing the appropriate inhaler device for the management of asthma and chronic obstructive pulmonary disease (COPD): a) assess patient's inspiratory ability; b) patient engagement and inhaler technique (from the algorithm developed by MGP Ltd, the publisher of Guidelines and the expert panel by them convened $\left.{ }^{20}\right)$. Adapted from Usmani 0 , et al. ${ }^{78}$, reproduced with permission.

DPI: dry powder inhalers; pMDI: pressurised metered-dose inhalers; SMI: soft-mist inhaler. 
their proper use ${ }^{62}$. Moreover, changing the inhaler device without the patient's input may result in worsened inhalation technique and critical errors, with a consequent reduction in adherence and disease control ${ }^{63}$. In contrast, choosing an optimal device with effective drug delivery to the lungs, may achieve better adherence, compliance, disease stability and potentially a reduction in the inhaled drug dose without compromising the therapeutic bene$\mathrm{fit}^{64}$. Indeed, a recent systematic review suggested that practitioners need to consider inhaler devices that can target the deep lung in order to achieve disease control ${ }^{65}$.

As with all pharmacological treatment decisions, it is important to actively involve patients in the choice of the inhaler device. Patients are in fact more likely to use a device effectively if they are comfortable with it ${ }^{66}$. Patient preferences regarding inhaler devices have been shown to significantly impact on disease management ${ }^{67}$. Characteristics of inhaler devices that affect patients' perceptions include appearance (size, weight, etc), ease and convenience of use, cost, brand, perceived efficacy, feelings about using the device in public, availability of the drug or device preparations, time needed to learn how to use and clean the device, and disposability/environmental issues ${ }^{68}$.

To facilitate good device-patient matching, physicians should be fully educated on device options to enable them to teach their patients proper inhaler technique and advise them on how to avoid common critical errors ${ }^{69}$. In fact, it is strongly recommended that healthcare professionals dedicate time for device education in their clinics and review inhalation technique at each patient visit ${ }^{70}$. With the aim to facilitate this guidance, the evidence or lack thereof underlying ten common 'inhaler lores' beliefs, has been recently reviewed in a practical consensus statement by a panel of experts, on the basis of their combined clinical and research expertise ${ }^{71}$.

\section{INNOVATIVE INHALER SOLUTIONS}

A variety of innovative strategies and tools are under evaluation and becoming available to improve patient inhaler technique and adherence. Among these, electronic health has shown to be effective in improving quality of care, adherence to therapy and early detection of disease worsening in patients with chronic airway diseases (Fig. 4$)^{72}$.

In particular, an increasing body of evidence seems to support the favourable role of inhaler trackers in the management of asthma and COPD. A training device together with a handheld, breath-actuated, microprocessor-controlled accessory has been effectively used in combination with pMDIs, to provide feedback on inhalation flow rate using audible prompts and indication lights ${ }^{73}$. Inhaler sensors to provide feedback to patients and detect environmental triggers that could trigger symptom worsening have been also developed for patients with asthma ${ }^{74}$. The use of monitors that connect to inhalers and provide real-time feedback and/or reminders on the quality of inhaler technique and proper adherence have shown improvements in medication adherence ${ }^{75}$. In a 24-week randomised controlled trial (RCT), the performance of an electronic inhaler device that recorded date, time and number of actuations, was 


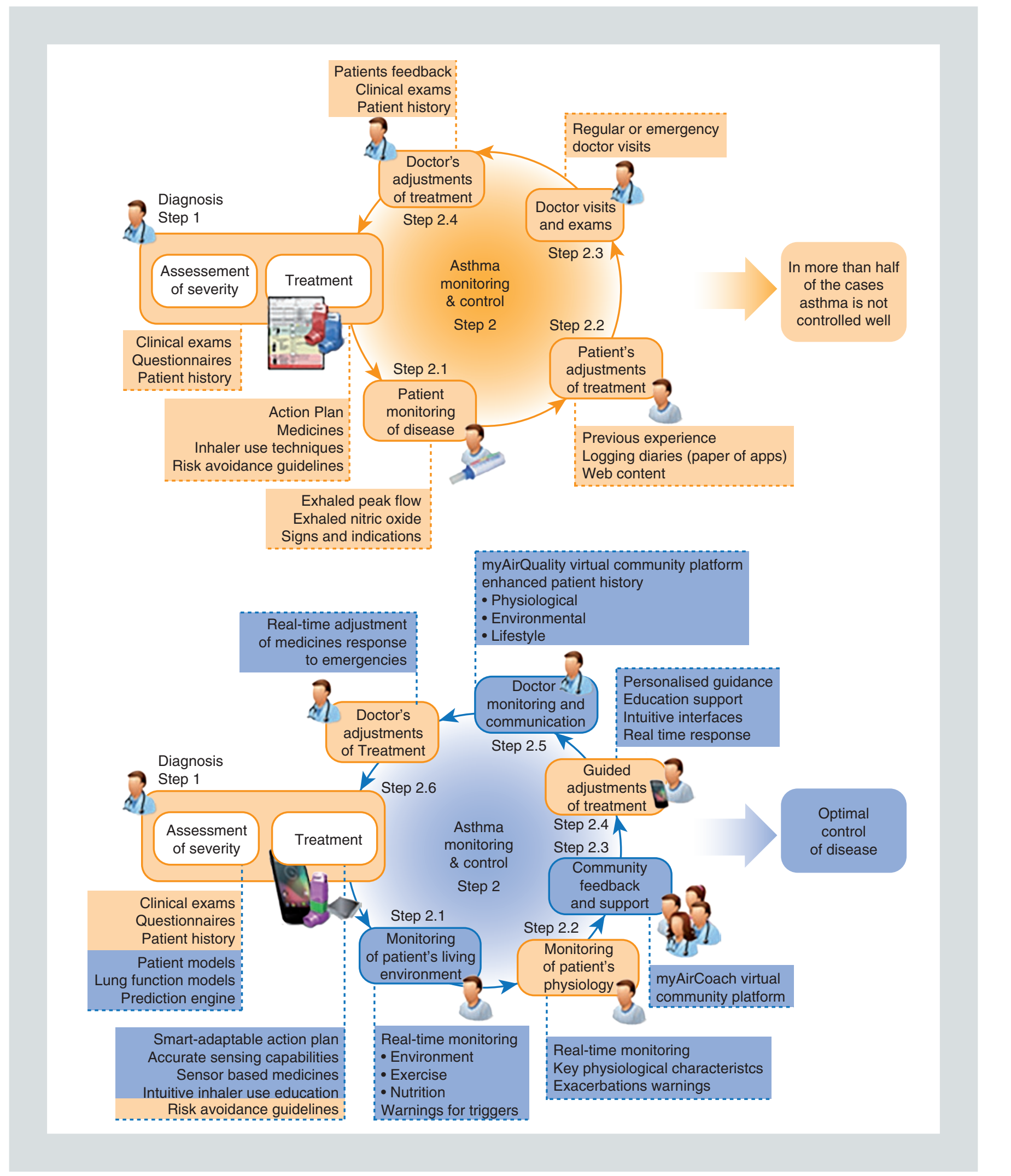

Figure 4. Components of a digital intervention to manage asthma (reproduced with permission from the myAirCoach EU Horizon 2020 funded project -grant agreement No. 643607; http://www.myaircoach.eu/). Current standard (in orange) and digital innovative (in blue) approaches to optimally managing asthma. 
investigated in more than 300 asthmatic patients. All monitors were loaded with study medication canisters and tested at the coordinating trial site before patient use. Of 2642 monitors dispensed to participants, only 76 (2.9\%) failed study monitor checks, 51 (1.9\%) malfunctioned before data upload and 93 (3.5\%) were lost or discarded by participants, suggesting that electronic monitoring may reliably help to assess patterns of medication use in asthmatic patients by reducing data $\operatorname{loss}^{76}$. The accuracy of an inhaler tracker recording actuations from a DPI device (Turbuhaler) was assessed over a 12-week period. The date and time of actuations were recorded in a paper diary and compared with data uploaded from the monitors. On a total of 2800 actuations performed, monitor sensitivity was $99.9 \%$ and positive predictive value was $99.9 \%{ }^{77}$. The consistency of an inhaler tracker for MDIs was conducted by testing the accuracy of the actuation $\log$ and the device functionality (i.e. monitor, buttons, and menu). Patients with asthma trialled the inhaler tracker device for seven days and recorded actuations in a diary. Uploaded data were compared to MDI dose counter and patient diaries. Baseline quality control showed that nine of ten devices had 100\% accuracy. Mean actuation log accuracy was $97 \%$ and reminders were $100 \%$ accurate. All devices successfully uploaded data. Average patient-rated difficulty of use was 6 of $100^{78}$. In another study, 18 participants from a six-month cluster RCT who received reminders for missed doses via an inhaler tracker adherence monitor were interviewed to explore their feedback on feasibility, utility, and sustainability. Overall, interviewees found the use of reminders and adherence feedback acceptable and useful for improving their adherence and confidence in asthma self-management ${ }^{79}$. Trials conducted with a more robust study design, on wider population samples and with a prolonged length of time are currently ongoing to further inform the debate on whether digital health interventions in asthma help patient outcomes ${ }^{80}$.

\section{CONCLUSIONS}

In order to demystify inhaler therapy, there is a real need to educate healthcare professionals, particularly doctors, about the importance of each of the inhaler device classes (pMDIs, DPIs, SMIs and nebulisers) used to deliver medication to patients with respiratory disease. There needs to be an appreciation by prescribers, and also patients, that the inhaler device is an integral part of the "drug prescription", and not a bystander. In the constrained time of the consultation with the patient, healthcare professionals need a pragmatic algorithm in choosing the right inhaler device for the right patient and one has recently been published ${ }^{59}$. In prescribing a device, healthcare professionals should take into consideration that a lot of work on inhaled therapies is funded by commercial entities with a vested interest, since this potentially represents a selection bias. Most importantly however, they should have proper knowledge on the key errors in the different device classes that will essentially make the inhaler clinically ineffective. Certainly, recent data show an association between inhaler misuse and worsened health outcomes, highlighting the importance of achieving optimal inhaler technique in the clinic. Additionally, the use of multiple different inhaler device classes is 
confusing for patients and should be avoided, as different inhalation manoeuvres are required for each device class, and recent data show multiple inhaler devices adversely affect disease outcomes. An inhaler check at every consultation is recommended as good practice, to ensure patients are not inadvertently increased in the drug dose, when the problem is essentially of being unable to engage with the inhaler device. In the last year, there has been a heightened interest in the role of digital intervention and innovation in managing the chronic airways disease of asthma and COPD. Although some initial studies are encouraging, there is a need for trials to be conducted with robust study design, on wider study samples and with a prolonged assessment time to clearly evaluate whether digital health interventions may significantly help patient outcomes and are cost-effective

\section{ACKNOWLEGDEMENTS}

\author{
Matteo Bonini is a recipient of a RESPIRE2 \\ ERS/Marie-Curie Fellowship.
}

\section{CONFLICTS OF INTEREST}

Dr. Bonini has received speaker fees from AstraZeneca, Menarini and Mundipharma International; Dr. Usmani reports grants and personal fees from AstraZeneca, Boehringer Ingelheim and Chiesi; personal fees from Aerocrine, Glaxosmithkline, Napp, Mundipharma, Sandoz, Takeda, Zentiva, Cipla and Pearl Therapeutics; grants from Prosonix and Edmond Pharma; everything outside the submitted work.

\section{REFERENCES}

1. Gibson G, Loddenkemper R, Lundbäck B, Sibille Y. Respiratory health and disease in Europe: the new European Lung White Book. Eur Respir J. 2013;42:559-63.

2. Bonini M, Usmani O. Monitoring asthma: current knowledge and future perspectives. Minerva Pneumologica. 2016;55:106-18.

3. Centers for Disease Control and Prevention. Chronic obstructive pulmonary disease among adults-United States, 2011. MMWR Morb Mortal Wkly Rep. 2012;61:938-43.

4. Lozano R, Naghavi M, Foreman K et al. Global and regional mortality from 235 causes of death for 20 age groups in 1990 and 2010: a systematic analysis for the Global Burden of Disease Study 2010. Lancet 2012;380:2095-2128.

5. Vos T, Flaxman A, Naghavi M et al. Years lived with disability (YLDs) for 1160 sequelae of 289 diseases and injuries 1990-2010: a systematic analysis for the Global Burden of Disease Study 2010. Lancet 2012;380:2163-96.

6. Mannino DM, Higuchi K, Yu TC, Zhou H, Li Y, Tian H, Suh K. Economic Burden of COPD in the Presence of Comorbidities. Chest. 2015;148:138-50

7. Bonini M, Usmani OS. The Importance of Inhaler Devices in the Treatment of COPD COPD Research and Practice. 2015:1;9.

8. Global Initiative for Asthma. Global Strategy for Asthma Management and Prevention, 2018. Available from http://ginasthma.org GOLD 2017 Global Strategy for the Diagnosis, Management and Prevention of COPD - Global Initiative for Chronic Obstructive Lung Disease - Available from: http:// goldcopd.org/

9. Bonini M, Usmani OS. The role of the small airways in the pathophysiology of asthma and chronic obstructive pulmonary disease. Ther Adv Respir Dis. 2015;9:281-93.

10. Dolovich MB, Dhand R. Aerosol drug delivery: developments in device design and clinical use. Lancet. 2011;377:1032-45.

11. Smaldone G, Berkland C, Gonda I, Mitchell J, Usmani OS, Clark A. Ask the experts: the benefits and challenges of pulmonary drug delivery. Ther Deliv. 2013;4:905-13.

12. Dekhuijzen R, Lavorini F, Usmani OS, van Boven JFM. Addressing the Impact and Unmet Needs of Nonadherence in Asthma and Chronic Obstructive Pulmonary Disease: Where Do We Go From Here? J Allergy Clin Immunol Pract. 2018;6:785-93.

13. Lavorini F, Usmani OS. Correct inhalation technique is critical in achieving good asthma control. Prim Care Respir J. 2013;22:385-6.

14. Usmani OS, Lavorini F, Marshall J. Critical inhaler errors in asthma and COPD: a systematic review of impact on health outcomes. Respir Res. 2018;19:10.

15. Dekhuijzen PN, Lavorini F, Usmani OS. Patients' perspectives and preferences in the choice of inhalers: the case for Respimat $(\circledR)$ or HandiHaler(®) Patient Prefer Adherence. 2016;10:1561-72.

16. Heyder J. Deposition of inhaled particles in the human respiratory tract and consequences for regional targeting in respiratory drug delivery. Proc Am Thorac Soc. 2004;1:315-20.

17. Hendeles L, Colice GL, Meyer RJ. Withdrawal of albuterol inhalers containing chlorofluorocarbon propellants. N Engl J Med. 2007;356:1344-51.

18. Lavorini F, Corrigan CJ, Barnes PJ et al. Retail sales of inhalation devices in European countries: so much for a global policy. Respir Med. 2011;105: 1099-113

19. https:/ / www.guidelines.co.uk/respiratory/inhaler-choice-guideline/ 252870.article. Accessed in April 2018.

20. Johal B, Howald M, Fischer M et al. Fine particle profile of fluticasone propionate/formoterol fumarate versus other combination products: the DIFFUSE study. Comb Prod Ther. 2013;3:39-51.

21. Chapman KR, Love L, Brubaker H. A comparison of breath-actuated and conventional metered-dose inhaler inhalation techniques in elderly subjects. Chest. 1993;104:1332-7.

22. Hampson NB, Mueller MP. Reduction in patient timing errors using a breath-activated metered dose inhaler. Chest. 1994;106:462-5 
23. Bell JH, Hartley PS, Cox JSG. Dry powder aerosols: I. A new powder inhalation device. J Pharm Sci. 1971;60:1559-64.

24. Thorsson L, Edsbäcker S, Källén A, Löfdahl CG. Pharmacokinetics and systemic activity of fluticasone via Diskus and pMDI, and of budesonide via Turbuhaler. Br J Clin Pharmacol. 2001;52:529e38.

25. Weuthen T, Roeder S, Brand P, Müllinger B, Scheuch G. In vitro testing of two formoterol dry powder inhalers at different flow rates. J Aerosol Med. 2002;15:297-303.

26. Loh CH, Peters SP, Lovings TM, Ohar JA. Suboptimal Inspiratory Flow Rates Are Associated with Chronic Obstructive Pulmonary Disease and All-Cause Readmissions. Ann Am Thorac Soc. 2017;14:1305-11.

27. Lavorini F, Pistolesi M, Usmani OS. Recent advances in capsule-based dry powder inhaler technology. Multidiscip Respir Med. 2017;12:11.

28. Corradi M, Chrystyn H, Cosio BG et al. NEXThaler, an innovative dry powder inhaler delivering an extrafine fixed combination of beclometasone and formoterol to treat large and small airways in asthma. Expert Opin Drug Deliv. 2014;11:1497-506.

29. Yawn BP, Colice GL, Hodder R. Practical aspects of inhaler use in the management of chronic obstructive pulmonary disease in the primary care setting. Int J Chron Obstruct Pulmon Dis. 2012;7:495-502.

30. Ibrahim M, Verma R, Garcia-Contreras L. Inhalation drug delivery devices: technology update. Med Devices (Auckl). 2015;8:131-9.

31. Jarvis S, Ind PW, Thomas C et al. Microbial contamination of domiciliary nebulisers and clinical implications in chronic obstructive pulmonary disease. BMJ Open Respir Res. 2014;1:e000018.

32. Lavorini F, Fontana GA, Usmani OS. New inhaler devices - the good, the bad and the ugly. Respiration. 2014;88:3-15.

33. Vogelmeier C, Kardos P, Hofmann T et al. Nebulised budesonide using a novel device in patients with oral steroid dependent asthma. Eur Respir J. 2015;45:1273-82.

34. Pham S, Ferguson GT, Kerwin E, Goodin T, Wheeler A, Bauer A. In Vitro Characterization of the eFlow Closed System Nebulizer with Glycopyrrolate Inhalation Solution. J Aerosol Med Pulm Drug Deliv. 2018;31:162-9.

35. Pepper AN, Cooke A, Livingston L et al. Asthma and chronic obstructive pulmonary disease inhalers: techniques for proper use. Allergy Asthma Proc. 2016;37:279-90.

36. Kunkel G, Magnussen H, Bergmann $K$ et al. Respimat (a new soft mist inhaler) delivering fenoterol plus ipratropium bromide provides equivalent bronchodilation at half the cumulative dose compared with a conventional metered dose inhaler in asthmatic patients. Respiration. 2000;67:306-14.

37. Brand P, Hederer B, Austen G, Dewberry H, Meyer T. Higher lung deposition with Respimat Soft Mist inhaler than HFA-MDI in COPD patients with poor technique. Int J Chron Obstruct Pulmon Dis. 2008;3:763-70.

38. Dalby RN, Eicher J, Zierenberg B. Development of respimat soft mist inhaler and its clinical utility in respiratory disorders. Med Devices Auckl. 2011;4:145e55

39. Anderson P. Use of Respimat Soft Mist inhaler in COPD patients. Int J Chron Obstruct Pulmon Dis. 2006;1:251-9.

40. Baiardini I, Braido F, Bonini M et al. Why do doctors and patients not follow guidelines? Curr Opin Allergy Clin Immunol. 2009; 9:228-33.

41. Slejko JF, Ghushchyan VH, Sucher B et al. Asthma control in the United States, 2008-2010: indicators of poor asthma control. J Allergy Clin Immunol. 2014; 133:1579-87.

42. Klok T, Kaptein AA, Duiverman EJ, Brand PL. It's the adherence, stupid (that determines asthma control in preschool children). Eur Respir J. 2014; 43:783-91.

43. Engelkes M, Janssens HM, de Jongste JC et al. Medication adherence and the risk of severe asthma exacerbations: a systematic review. Eur Respir J. 2015; 45:396-407.

44. Sulaiman I, Greene G, MacHale E et al. A randomised clinical trial of feedback on inhaler adherence and technique in patients with severe uncontrolled asthma. Eur Respir J. 2018 Jan 4;51.

45. Sulaiman I, Cushen B, Greene G et al. Objective Assessment of Adherence to Inhalers by Patients with Chronic Obstructive Pulmonary Disease. Am
J Respir Crit Care Med. 2017;195:1333-43.Cushen B, Sulaiman I, Greene G et al. The Clinical Impact of Different Adherence Behaviours in Patients with Severe COPD. Am J Respir Crit Care Med. 2018;197:1630-3. Sanduzzi A, Balbo P, Candoli P, et al. COPD: adherence to therapy. Multidiscip Respir Med. 2014;9:60.

46. Lavorini F, Magnan A, Dubus JC et al. Effect of incorrect use of dry powder inhalers on management of patients with asthma and COPD. Respir Med. 2008;102:593-604.

47. Price DB, Román-Rodríguez M, McQueen RB et al. Inhaler Errors in the CRITIKAL Study: Type, Frequency, and Association with Asthma Outcomes. J Allergy Clin Immunol Pract. 2017;5:1071-1081.e9.

48. Braido F, Chrystyn H, Baiardini I et al. Respiratory Effectiveness Group "Trying, But Failing" - The Role of Inhaler Technique and Mode of Delivery in Respiratory Medication Adherence. J Allergy Clin Immunol Pract. 2016 4:823-32.

49. Westerik JA, Carter V, Chrystyn H et al. Characteristics of patients making serious inhaler errors with a dry powder inhaler and association with asthma-related events in a primary care setting. J Asthma. 2016;53:321-9.

50. Sanchis J, Corrigan C, Levy ML, Viejo JL. ADMIT Group. Inhaler devices - from theory to practice. Respir Med. 2013;107:495-502.

51. Chrystyn H, van der Palen J, Sharma R et al. Device errors in asthma and COPD: systematic literature review and meta-analysis. NPJ Prim Care Respir Med. 2017;27:22.

52. Usmani OS, Lavorini F, Marshall J et al. Critical inhaler errors in asthma and COPD: a systematic review of impact on health outcomes. Respir Res. 2018;19:10.

53. Rogliani P, Calzetta L, Coppola A et al. Optimizing drug delivery in COPD the role of inhaler devices. Respir Med. 2017;124:6-14.

54. Usmani OS, Biddiscombe MF, Barnes PJ. Regional lung deposition and bronchodilator response as a function of beta2-agonist particle size. Am J Respir Crit Care Med. 2005;172:1497-504.

55. Usmani OS, Biddiscombe MF, Nightingale JA, Underwood SR, Barnes PJ Effects of bronchodilator particle size in asthmatic patients using monodisperse aerosols. J Appl Physiol (1985). 2003;95:2106-12.

56. Biddiscombe MF, Usmani OS, Barnes PJ. A system for the production and delivery of monodisperse salbutamol aerosols to the lungs. Int J Pharm. 2003;254:243-53.

57. https://www.guidelines.co.uk/respiratory/inhaler-choice-guideline/252870 Accessed in April 2018.

58. http://www.respiratoryfutures.org.uk/media/69774/ukig-inhaler-standards-january-2017. Accessed in April 2018.

59. Rau JL. The inhalation of drugs: advantages and problems. Respir Care 2005;50:367-82.

60. Roggeri A, Micheletto C, Roggeri DP. Inhalation errors due to device switch in patients with chronic obstructive pulmonary disease and asthma: critical health and economic issues. Int J Chron Obstruct Pulmon Dis. 2016;11:597-602.

61. Usmani OS, Kemppinen A, Gardener E et al. A Randomized Pragmatic Trial of Changing to and Stepping Down Fluticasone/Formoterol in Asthma. J Allergy Clin Immunol Pract. 2017;5:1378-87.e5.

62. Sonnappa S, McQueen B, Postma DS et al. Extrafine Versus Fine Inhaled Corticosteroids in Relation to Asthma Control: A Systematic Review and Meta-Analysis of Observational Real-Life Studies. J Allergy Clin Immunol Pract. 2018;6: 907-915.e7.

63. Vincken W, Dekhuijzen PR, Barnes P. The ADMIT series - issues in inhalation therapy. 4) How to choose inhaler devices for the treatment of COPD. Prim Care Respir J. 2010;19:10-20.

64. Dal Negro RW, Povero M. Acceptability and preference of three inhalation devices assessed by the Handling Questionnaire in asthma and COPD patients. Multidiscip Respir Med. 2015;11:7.

65. Hodder R, Price D. Patient preferences for inhaler devices in chronic obstructive pulmonary disease: experience with Respimat Soft Mist inhaler. Int J Chron Obstruct Pulmon Dis. 2009;4:381-90.

66. Laube BL, Janssens HM, De Jongh FH et al. What the pulmonary specialist should know about the new inhalation therapies. Eur Respir J. 2011;37:1308-31 
67. Pothirat $\mathrm{C}$, Chaiwong $\mathrm{W}$, Phetsuk $\mathrm{N}$ et al. Evaluating inhaler use technique in COPD patients. Int J Chron Obstruct Pulmon Dis. 2015;10:1291-8.

68. Levy ML, Dekhuijzen PN, Barnes PJ et al. Inhaler technique: facts and fantasies. A view from the Aerosol Drug Management Improvement Team (ADMIT). NPJ Prim Care Respir Med. 2016;26:16017.

69. Kikidis D, Konstantinos V, Tzovaras D, Usmani OS. The Digital Asthma Patient: The History and Future of Inhaler Based Health Monitoring Devices. J Aerosol Med Pulm Drug Deliv. 2016;29:219-32.

70. Lavorini F, Levy ML, Corrigan C et al. The ADMIT series - issues in inhalation therapy. Training tools for inhalation devices. Prim Care Respir J. 2010;19:335-41

71. Su JG, Barrett MA, Henderson $\mathrm{K}$ et al. Feasibility of deploying inhaler sensors to identify the impacts of environmental triggers and built environment factors on asthma short-acting bronchodilator use. Environ Health Perspect. 2017;125:254-61.

72. Foster JM, Usherwood T, Smith L et al. Inhaler reminders improve adherence with controller treatment in primary care patients with asthma. J Allergy Clin Immunol. 2014;134:1260-8.e1263.

73. Patel M, Pilcher J, Travers J et al. Use of metered-dose inhaler electronic monitoring in a real-world asthma randomized controlled trial. J Allergy
Clin Immunol Pract 2013; 1:83-91. Erratum in: J Allergy Clin Immunol Pract. 2013;1:314.

74. Pilcher J, Shirtcliffe P, Patel M et al. Three-month validation of a turbuhaler electronic monitoring device: implications for asthma clinical trial use. BMJ Open Respir Res. 2015;2:e000097.

75. Foster JM, Smith L, Usherwood T et al. The reliability and patient acceptability of the SmartTrack device: a new electronic monitor and reminder device for metered dose inhalers. J Asthma. 2012;49:657-62.

76. Foster JM, Reddel HK, Usherwood T et al. Patient-perceived acceptability and behaviour change benefits of inhaler reminders and adherence feedback: a qualitative study. Respir Med. 2017;129:39-45.

77. Honkoop PJ, Simpson A, Bonini M et al. MyAirCoach: the use of home-monitoring and mHealth systems to predict deterioration in asthma control and the occurrence of asthma exacerbations; study protocol of an observational study. BMJ Open. 2017;7:e013935.

78. Usmani O, Capstick T, Chowhan H, Scullion J. Guidelines summarising clinical guidelines for primary care. 66th ed. Chesham: MGP Ltd; March 2018:280-2. Available at: www.guidelines.co.uk/respiratory/inhaler-choiceguideline. 